\title{
Monitoring and kinetic analysis of the molecular interactions by which a repressor protein, PhaR, binds to target DNAs and poly[(R)-3-hydroxybutyrate]
}

\author{
Miwa Yamada ${ }^{1,4}$, Shuntaro Takahashi ${ }^{2,5}$, Yoshio Okahata ${ }^{2}$, Yoshiharu Doi ${ }^{3}$ and Keiji Numata ${ }^{\text {* }}$
}

\begin{abstract}
The repressor protein PhaR, which is a component of poly[(R)-3-hydroxybutyrate] granules, functions as a repressor of the gene expression of the phasin PhaP and of PhaR itself. We used a quartz crystal microbalance to investigate the binding behavior by which PhaR in Ralstonia eutropha H16 targets DNAs and amorphous poly[(R)-3hydroxybutyrate] thin films. Binding rate constants, dissociation rate constants, and dissociation constants of the binding of PhaR to DNA and to amorphous poly[(R)-3-hydroxybutyrate] suggested that PhaR bind to both in a similar manner. On the basis of the binding rate constant values, we proposed that the phaP gene would be derepressed in harmony with the ratio of the concentration of the target DNA to the concentration of amorphous poly[(R)-3-hydroxybutyrate] at the start of poly[(R)-3-hydroxybutyrate] synthesis in R. eutropha H16.
\end{abstract}

Keywords: Polyhydroxyalkanoate, Autoregulator protein PhaR, Kinetic analysis, Ralstonia eutropha H16

\section{Introduction}

Polyhydroxyalkanoate (PHA), an eco-friendly and biodegradable polyester, is synthesized by a variety of bacteria, as their intracellular storage material for carbon and energy (Doi et al. 1995; Steinbuchel and Fuchtenbusch 1998; Sudesh et al. 2000). In bacterial cells, PHA forms granules that are covered with a layer composed of proteins and phospholipids (Potter et al. 2002). The most abundant constituent of this layer is phasin (PhaP). The presence of PhaP on the surface of PHA granules contributes to the reduction in size of PHA granules as well as to the slight enhancement of PHA production (Kojima et al. 2006; Potter et al. 2002; Potter and Steinbuchel 2005). Recently, the ability of PhaP to bind to a hydrophobic surface was used to develop methods for protein purification, drug delivery, and tissue engineering applications in in vitro experiments (Backstrom et al. 2007; Banki et al. 2005; Wang et al. 2008). In the cells of microorganisms, a repressor protein PhaR regulates the expression of phaP

\footnotetext{
* Correspondence: keiji.numata@riken.jp

${ }^{1}$ Enzyme Research Team, RIKEN Biomass Engineering Program, RIKEN, 2-1,

Hirosawa, Wako-shi, Saitama 351-0198, Japan

Full list of author information is available at the end of the article
}

and phaR. PhaR has also been reported to sense the presence of PHA and to interact with nascent PHA granules, resulting in the derepression of phaP expression (Potter et al. 2002; Potter and Steinbuchel 2005). The presence of genes homologous to PhaR and PhaP in the genomes of various PHA-producing bacteria suggests that a similar regulatory system by PhaR is likely to exist in PHAproducing bacteria (Eugenio et al. 2010; Kojima et al. 2006; Maehara et al. 2002; Yamada et al. 2007; Yamashita et al. 2006). This regulatory system of PHA production through phaR and phaP expression can be applied in a two-hybrid system for protein-protein interaction (Wang et al. 2011). Therefore, understanding of the regulatory system provides meaningful benefit to not only basic science but also applications in various fields such as industry and medicine.

In previous studies, the binding behaviors of PhaR to target DNA (including the promoter region of phaP) and to melt-crystallized thin films of poly[(R)-3-hydroxybutyrate] $[\mathrm{cr}-\mathrm{P}(3 \mathrm{HB})]$ were investigated using surface plasmon resonance (SPR) and quartz crystal microbalance (QCM) measurements (Yamada et al. 2007; Yamashita et al. 2006). However, kinetic parameters such as the binding rate 
constant $\left(k_{\text {on }}\right)$ and dissociation rate constant $\left(k_{\text {off }}\right)$ by which PhaR targets DNA and $\mathrm{P}(3 \mathrm{HB})$ have not been determined thus far. These kinetics and stoichiometric analyses will contribute new insights into the behavior of PhaR in the regulatory system of phaP expression. In order to determine the precise kinetic parameters, we selected a multichannel QCM sensing system to monitor the binding reaction of PhaR from Ralstonia eutropha H16 to target DNAs (including the promoter regions of phaP and phaR) and thin films of amorphous $\mathrm{P}(3 \mathrm{HB})$ [am- $\mathrm{P}(3 \mathrm{HB})$ ] derived from atactic $\mathrm{P}(3 \mathrm{HB})$. This is because the $\mathrm{P}(3 \mathrm{HB})$ native granule is composed of am- $\mathrm{P}(3 \mathrm{HB})$. Recently, the regulatory system of PHA production through phaR and phaP expression has been applied in studies of protein-protein interaction, protein purification, drug delivery, and tissue engineering. The insights gained into this regulation mechanism in this study have the potential to improve applications in white biotechnology. We have determined kinetic parameters based on mass changes on the DNA-immobilized and am-P(3HB)-coated QCM oscillators, and discuss the binding behavior of $\mathrm{PhaR}$ with target DNA and am- $\mathrm{P}(3 \mathrm{HB})$.

\section{Methods}

Expression and purification of autoregulator protein PhaR All chemical reagents were purchased from Wako Pure Chemicals (Osaka, Japan). The phaR gene from R. eutropha H16 was cloned using a TOPO TA cloning Kit (Invitrogen, Carlsbad, CA) with the forward primer $5^{\prime}$-CACCATGGCCACGACCAAAAAAGG-3' and reverse primer 5'-TTACTTCTTGTCCGGCTGGT-3'. The resultant plasmid is referred to as pET100/D-TOPO$\mathrm{PhaR}_{\mathrm{Re}}$. The expression of the phaR gene was driven by the T5 promoter, which is inducible with isopropyl- $\alpha-\mathrm{D}$ thiogalactopyranoside (IPTG). The constructed plasmid was introduced into Escherichia coli BL21(DE3). Transformants were grown in $1200 \mathrm{~mL}$ of Luria-Bertani medium containing ampicillin $(100 \mu \mathrm{g} / \mathrm{mL})$ and kanamycin $(50 \mu \mathrm{g} / \mathrm{mL})$. They were cultivated at $30^{\circ} \mathrm{C}$ until the $\mathrm{OD}_{600}$ of the culture reached 0.5. After the addition of IPTG (final concentration of $1 \mathrm{mM}$ ), the transformants were grown for an additional $5 \mathrm{~h}$. The cells were then harvested and washed with chilled buffer A $(50 \mathrm{mM}$ sodium phosphate ( $\mathrm{pH} 8.0$ ) containing $300 \mathrm{mM} \mathrm{NaCl}$ and $10 \mathrm{mM}$ imidazole), and were suspended in $60 \mathrm{~mL}$ of the same buffer. The suspension was stored at $-80^{\circ} \mathrm{C}$ until use. The suspension was thawed on ice and disrupted by sonic oscillation, also on ice. The cell debris was then removed by centrifugation at $15000 \times g$ for $60 \mathrm{~min}$ at $4^{\circ} \mathrm{C}$, and the supernatant was collected for purification. The experiments were carried out at $4^{\circ} \mathrm{C}$ throughout the purification steps. The crude extract was shaken gently with nickel-nitrilotriacetic acid agarose (Qiagen, Valencia, CA) for $1 \mathrm{~h}$. The mixture was then poured into a column.
The column was washed with buffer A containing $20 \mathrm{mM}$ imidazole, and then the His-tagged protein was eluted with buffer A containing $250 \mathrm{mM}$ imidazole. The eluates containing PhaR were dialyzed against $10 \mathrm{mM}$ HEPES ( $\mathrm{pH}$ 7.4) containing $150 \mathrm{mM} \mathrm{NaCl}$ and $3 \mathrm{mM}$ EDTA and stored at $-80^{\circ} \mathrm{C}$. The protein concentration was determined using a Bio-Rad Protein Assay Kit (Bio-Rad, Hercules, CA) with bovine serum albumin as the standard. Proteins were separated by sodium dodecyl sulfate (SDS)-12.5\% polyacrylamide gel electrophoresis (PAGE) and stained with Coomassie brilliant blue (CBB) R-250 (BioRad) as described by Laemmli (Figure 1).

\section{Calibration of 27-MHz QCM in aqueous solution}

The QCM apparatus was an AFFINIX Q4 (Initium Co., Ltd., Tokyo, Japan) with 4 500- $\mu \mathrm{L}$ cells equipped with a 27-MHz QCM plate $(8.7 \mathrm{~mm}$ diameter quartz plate and $5.7 \mathrm{~mm}^{2}$ area $\mathrm{Au}$ electrode) at the bottom of the cell and a stirring bar with a temperature control system (Takahashi et al. 2007; Takahashi et al. 2008). The relationship between mass and frequency changes in aqueous solutions when DNAs and/or proteins were immobilized onto the QCM was calibrated by comparing it against values in the air phase. One $\mathrm{Hz}$ of frequency represents a $0.10 \mathrm{ng} \mathrm{\textrm {cm } ^ { - 2 }}$ mass increase on the QCM plate. The noise level of the $27-\mathrm{MHz}$ QCM was $\pm 2 \mathrm{~Hz}$ in buffer solutions at $25^{\circ} \mathrm{C}$, and the stability of the frequency was $\pm 2 \mathrm{~Hz}$ for $1 \mathrm{~h}$ in buffer at $25^{\circ} \mathrm{C}$.

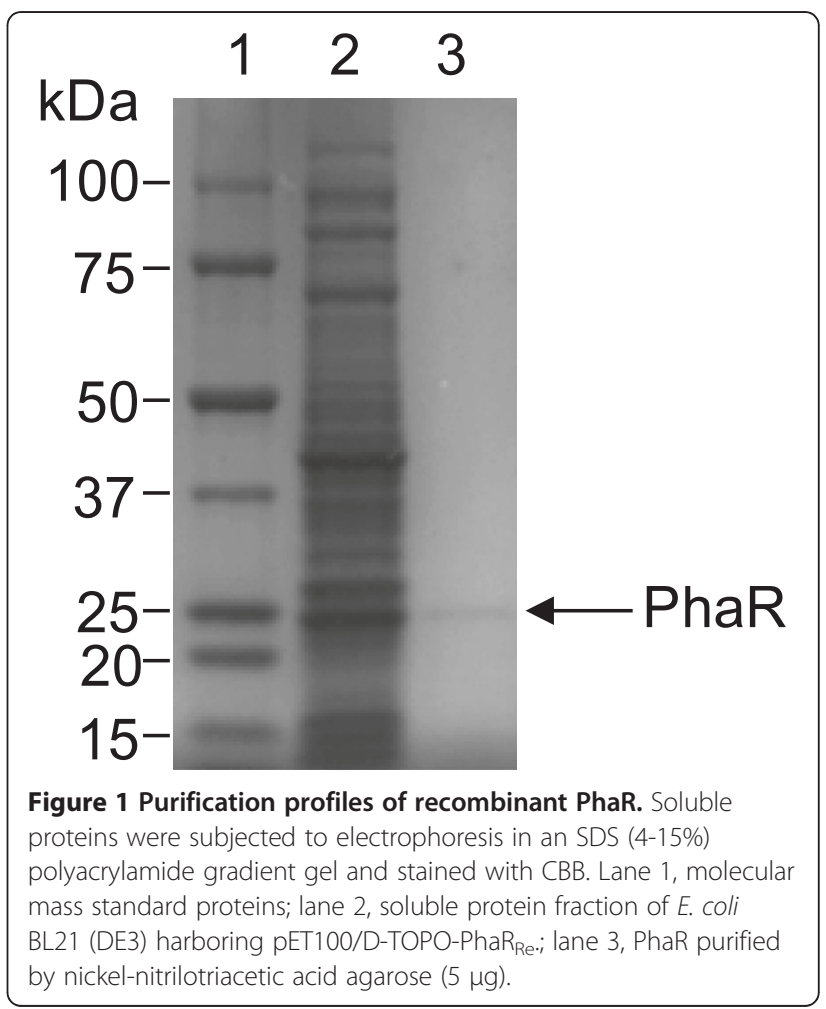




\section{Preparation of the DNA-Immobilized QCM Oscillator}

The structures of the biotinylated oligonucleotides used in this study are summarized in Table 1: they consisted of 5-biotinylated dsDNA (50 bp) containing a site recognized by PhaR dsDNA (phaP promoter region DNA and phaR promoter region DNA) and no-site dsDNA (control DNA). Oligonucleotide duplexes were formed by mixing a biotinylated strand and its complementary strand in a solution of $10 \mathrm{mM}$ Tris- $\mathrm{HCl}(\mathrm{pH} 7.8), 1 \mathrm{mM}$ EDTA, and $200 \mathrm{mM} \mathrm{NaCl}$, and then boiling for a few minutes, followed by cooling to room temperature over $1 \mathrm{~h}$. These oligonucleotides were immobilized on a cleaned $\mathrm{Au}$ electrode of the QCM using biotin-avidin linkage according to the methods described in a previous paper (Okahata et al. 1998). The amount of immobilized DNA was maintained at $191 \mathrm{ng}(0.55-0.02 \mathrm{pmol}) \mathrm{cm}^{-2}$, which corresponds to $1 \%$ coverage of the Au surface $\left(5.7 \mathrm{~mm}^{2}\right)$. This would allow sufficient space to accommodate the binding of a large enzyme molecule.

\section{Preparation of $\mathrm{P}(3 \mathrm{HB})$ thin films}

QCM oscillators were washed with a freshly prepared Piranha solution of $\mathrm{H}_{2} \mathrm{O}_{2} / \mathrm{H}_{2} \mathrm{SO}_{4}(1 / 3 \mathrm{v} / \mathrm{v})$ and were rinsed several times with Milli-Q water. (Caution: Piranha solution is very oxidative and dangerous, and direct contact should be avoided). Thin films of $\mathrm{P}(3 \mathrm{HB})$ were prepared on the QCM oscillators by casting $300 \mu \mathrm{l}$ of chloroform solutions (1.0-1.5 wt\%) of the polymers on a spin-coater at $4000 \mathrm{rpm}$ under dry air.

\section{Reactions in the DNA-immobilized or am-P(3HB) coated QCM oscillator}

Enzyme reactions in a DNA-immobilized or am- $\mathrm{P}(3 \mathrm{HB})$ coated QCM cell were performed with $500 \mu \mathrm{L}$ of assay buffer (10 mM HEPES (pH 7.4), $150 \mathrm{mM} \mathrm{NaCl}$, and $0.002 \%$ Tween 20 ). The frequency changes in response to the addition of enzymes were then followed over time. The solution was vigorously stirred to avoid any effects from the slow diffusion of the enzymes. The stirring did not affect the stability or magnitude of the frequency changes.

\section{Results}

In order to measure the binding behavior of PhaR to 5 -biotinylated dsDNAs (50 bp), the DNA fragments with phaR-binding sequences (the promoter regions of phaR and phaP) and a non-specific sequence (negative control) were immobilized on the electrode of a QCM by biotin-avidin linkage, according to methods outlined in previous papers (Matsuno et al. 2001; Okahata et al. 1998). PhaR was purified using the His-tag purification system, and the purity of PhaR was confirmed by SDSPAGE (Figure 1). The binding behaviors of PhaR to the DNA fragments were monitored. Figure 2A shows a typical frequency decrease (mass increase) as a function of time, in response to the addition of PhaR. PhaR mainly bound to the DNA containing the phaP promoter region (curve a), and barely bound to the DNA containing the phaR promoter region (curve b) and the control DNA (curve $\mathrm{c}$ ). Figure $2 \mathrm{~B}$ shows that the amount of the bound PhaR $(\Delta m)$ followed a saturation curve as a function of the PhaR concentration ([PhaR]). These binding curves formed a sigmoid curve.

Next, we attempted to determine the kinetic parameters ( $k_{\text {on }}, k_{\text {off }}$, and $K_{\mathrm{d}}$ values) of the binding of PhaR to DNAs. The process by which PhaR binds to the DNAs is described by Equation 1 (Okahata et al. 1998). The amount of the DNA/PhaR complex ([DNA/PhaR]) formed after the injection is given by Equations 2 and 3 . The fitting curves of the decreases in frequency at various PhaR concentrations gave the relaxation time $(\tau)$ and the relaxation rate $\left(\tau^{-1}\right)$ of PhaR binding. When the concentration of PhaR increased from 2.5 to $10 \mathrm{nM}$, the amount of PhaR bound to the DNA increased (Figure 3A). In addition, the $\tau$ value decreased with the concentration of PhaR. The $1 / \tau$ value at each PhaR concentration was plotted against the concentrations of PhaR, according to Equation 4 (Figure 3B). The PhaR binding and dissociation rate constants ( $k_{\text {on }}$ and $\left.k_{\text {off }}\right)$ were obtained from the slope and the intercept of Equation 4 , respectively. The $K_{\mathrm{d}}$ values were obtained from the ratio $k_{\text {off }} / k_{\text {on }}$. The kinetic parameters, $k_{\text {on }}, k_{\text {off }}, K_{\mathrm{d}}$, for the target DNAs and control DNA are summarized in Table 1 .

Table 1 Kinetic parameters for the binding of PhaR to DNAs and P(3HB) on the 27-MHz QCM

\begin{tabular}{|c|c|c|c|c|}
\hline Targets $^{\mathrm{b}}$ & DNA sequence $^{c}$ & $k_{\mathrm{on}}^{\mathrm{d}}\left(10^{-4} \mathrm{M}^{-1} \mathrm{~s}^{-1}\right)$ & $k_{\text {off }}^{c}\left(10^{-3} s^{-1}\right)$ & $K_{\mathrm{d}}^{e}\left(10^{-7} \mathrm{M}\right)$ \\
\hline Control DNA ${ }^{f}$ & 5'bio-TCGTTTAACGAGCCCGTATTTCCCCTCTACCTITAGAGGACACCTAAC-3' & 0.4 & 0.7 & 18 \\
\hline phaP1 promoter ${ }^{9}$ & 5'bio-GGCGCATTTCTTATTTTGGTGCGCCGCAACAATTCCTATTTTAGGGGCGCC-3' & $6.0 \pm 0.4$ & $1.7 \pm 0.4$ & $3.2 \pm 0.9$ \\
\hline phaR promoter ${ }^{f}$ & 5'bio-TCACGCGTTTAGCCATAGCGGGCGCGGTAGACGAACAACAGCACGGCCGG-3' & 0.5 & 0.9 & 18 \\
\hline $\mathrm{am}-\mathrm{P}(3 \mathrm{HB})^{\mathrm{g}}$ & & $7.0 \pm 3.8$ & - h & $-h$ \\
\hline
\end{tabular}

a $10 \mathrm{mM}$ HEPES buffer solution ( $\mathrm{pH}$ 7.4) containing $150 \mathrm{mM} \mathrm{NaCl}$ and $0.002 \%$ Tween $20,25^{\circ} \mathrm{C} .{ }^{\mathrm{b}} 5^{\prime}$-biotinylated dsDNA immobilized on an avidin-covered QCM plate.

Amorphous-P(3HB) thin film was prepared by casting chloroform solution (1.0 wt\%) of the isotactic P $\left[(R),(S)-3\right.$-hydroxybutyrate]. ${ }^{c}$ The bold type indicates the DNA binding site of PhaR revealed by DNase I footprinting (4). ${ }^{\mathrm{d}} k_{\text {on }}$ and $k_{\text {off }}$ were obtained from Eq. $4 .{ }^{e} K_{\mathrm{d}}$ was calculated as $k_{\text {off }} / k_{\text {on }}$. ${ }^{\mathrm{f}}$ The data are from 2 independent experiments. ${ }^{g}$ Amorphous $\mathrm{P}(3 \mathrm{HB})$; the data are from 3 independent experiments. ${ }^{\mathrm{h}} K_{\mathrm{d}}$ value could not be calculated due to a negative $\mathrm{k}_{\text {off }}$ value. 


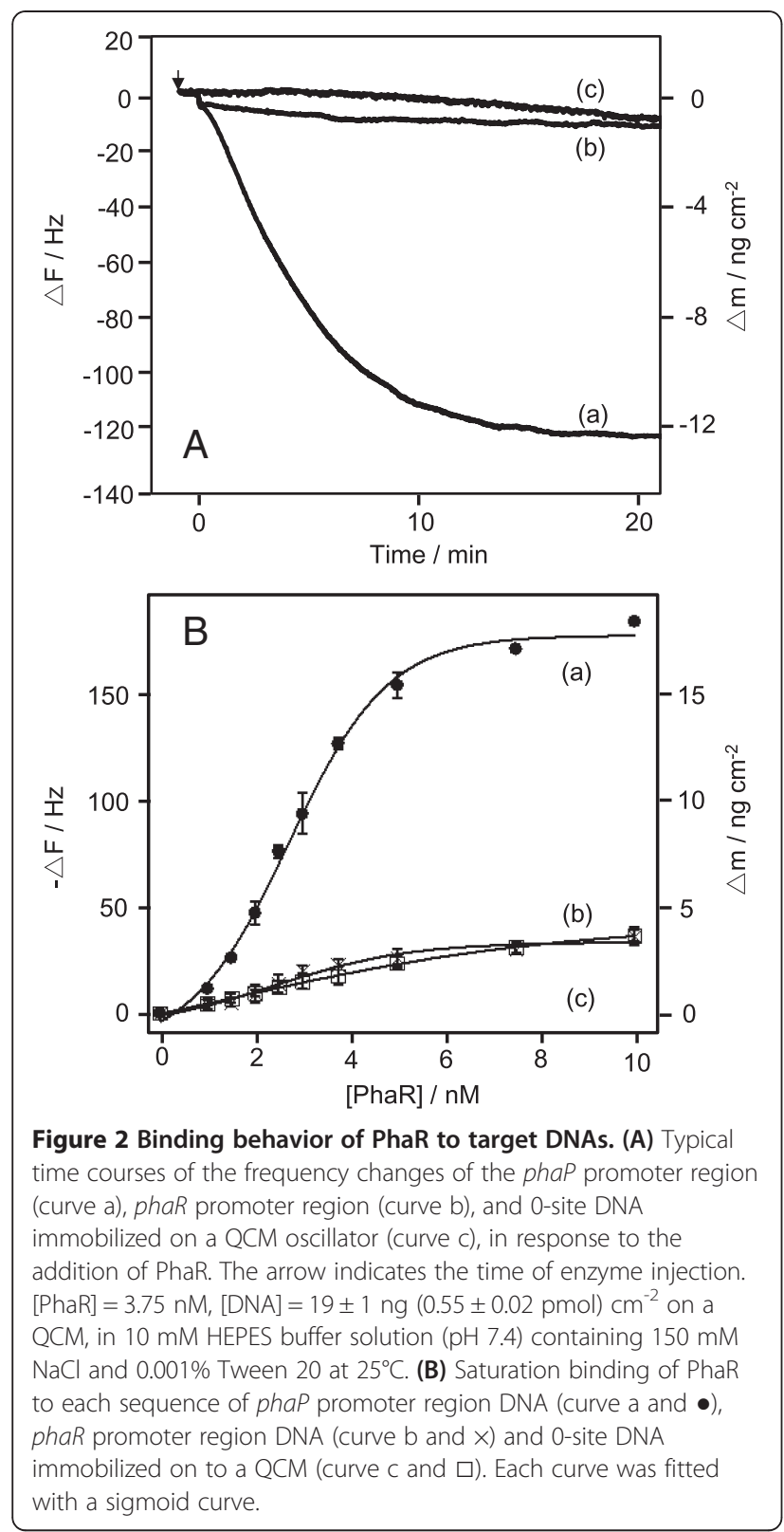

$$
\begin{aligned}
& \stackrel{k_{\text {on }}}{\rightleftarrows} \mathrm{PhaR} / \mathrm{DNA} \\
& k_{\text {off }} \\
& {[\mathrm{DhaR}+\mathrm{DNA} / \mathrm{PhaR}]_{t}=[\mathrm{DNA} / \mathrm{PhaR}]_{\max }\{1-\exp (-t / \tau)\}} \\
& \Delta m_{t}=\Delta m_{\max }\{1-\exp (-t / \tau)\} \\
& 1 / \tau=k_{\text {on }}[\mathrm{PhaR}]+k_{\text {off }}
\end{aligned}
$$

We also investigated the binding of $\mathrm{PhaR}$ to $\mathrm{P}(3 \mathrm{HB})$ granules in microorganisms using a QCM sensor coated
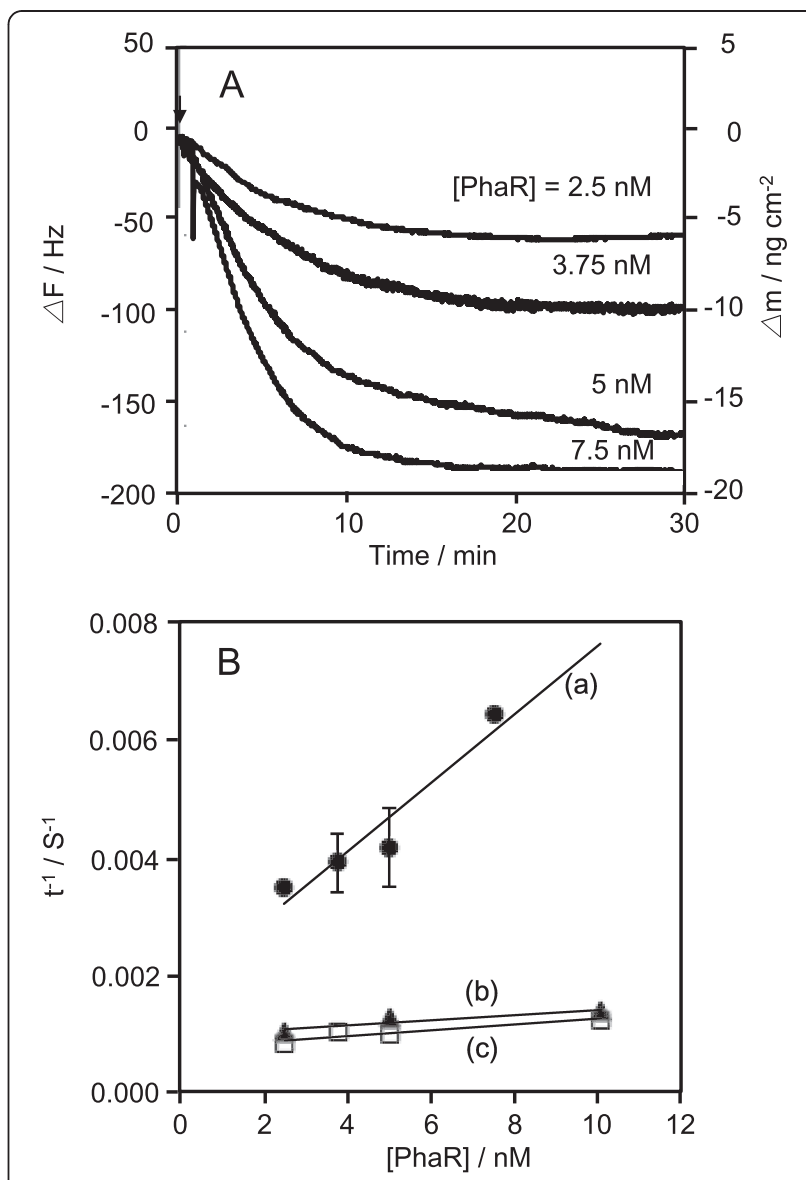

Figure 3 The influence of PhaR concentrations on the rate of binding to target DNAs. (A) Binding behaviors of PhaR to the DNA including the phaP promoter region in response to changes in PhaR concentration. The arrow indicates the time of enzyme injection.

(B) Linear reciprocal plots of the relaxation rate $\left(\tau^{-1}\right)$ against the PhaR concentrations according to Eq. (4) in the text.

with am- $\mathrm{P}(3 \mathrm{HB})$ (Figure $4 \mathrm{~A})$. This is because the $\mathrm{P}(3 \mathrm{HB})$ native granules are mainly composed of am- $\mathrm{P}(3 \mathrm{HB})$. The amount of PhaR bound on am- $\mathrm{P}(3 \mathrm{HB})$ thin films increased when the concentration of PhaR increased from 1 to $15 \mathrm{nM}$ (Figure 4B and C). Interestingly, as with the binding curve against the target DNA, the binding curve against am- $\mathrm{P}(3 \mathrm{HB})$ exhibited a sigmoid curve. These results indicated that $\mathrm{PhaR}$ bound to $\mathrm{P}(3 \mathrm{HB})$ in a similar manner as to DNA. The kinetic parameters $\left(k_{\text {on }}\right.$ and $\left.k_{\text {off }}\right)$ were calculated from Equations 1 to 4 (Figure $4 \mathrm{D}$ and Table 1). The $k_{\text {on }}$ value for am- $\mathrm{P}(3 \mathrm{HB})\left(k_{\text {on }}=7.0 \pm 3.8 \times\right.$ $\left.10^{4} \mathrm{M}^{-1} \mathrm{~s}^{-1}\right)$ showed no significant difference from that for DNA containing the phaP promoter region $\left(k_{\mathrm{on}}=6.0 \pm\right.$ $\left.0.4 \times 10^{4} \mathrm{M}^{-1} \mathrm{~s}^{-1}\right)$.

\section{Discussion}

In order to understand the regulatory system governing PHA production in detail, we investigated the binding behaviors of PhaR to the target DNA (containing the 


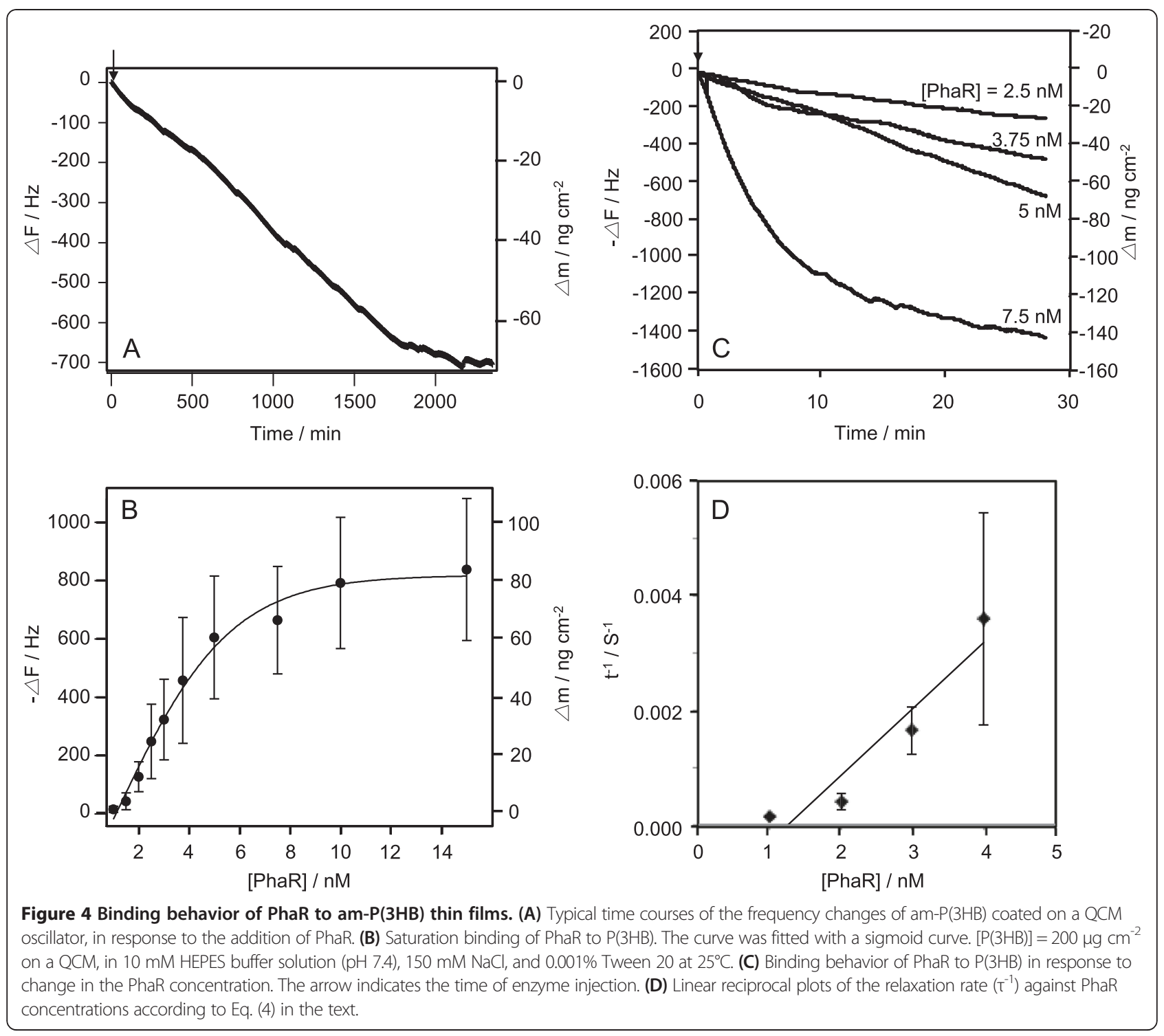

promoter region of phaP) and to $\mathrm{P}(3 \mathrm{HB})$, using $\mathrm{QCM}$ measurements. Regarding PhaR-DNA binding, Figure 2A shows that PhaR mainly bound to the DNA containing the phaP promoter region (curve a), and barely bound to the DNA containing the phaR promoter region (curve b) or to the control DNA (curve c). The binding curve of PhaR to the phaP promoter region showed sigmoid curve, implying that PhaR binds to target DNA in a cooperative reaction. The SPR analysis of PhaR-DNA binding in previous studies was not capable of monitoring the initial binding of PhaR, because the concentration of PhaR $(10 \mu \mathrm{M})$ was higher than in the present experimental conditions (2.5 to $10 \mathrm{nM}$ ) (Kojima et al. 2006; Maehara et al. 2002). The higher binding affinity of PhaR to the phaP promoter region accorded with the results of gel-mobility-shift assays (Maehara et al. 2002). The DNA fragments with the phaP promoter region shifted at a lower concentration of PhaR compared to the DNA fragments that contained the phaR promoter region (Potter et al. 2002).

The binding rate constant for the DNA containing the phaR promoter region $\left(k_{\text {on }}=0.5 \times 10^{4} \mathrm{M}^{-1} \mathrm{~s}^{-1}\right)$ was similar to the parameters for the control DNA $\left(k_{\text {on }}=0.4 \times\right.$ $10^{4} \mathrm{M}^{-1} \mathrm{~s}^{-1}$ ) (Table 1). Moreover, the dissociation rate constant for the DNA containing the phaP promoter region $\left(k_{\text {off }}=1.7 \pm 0.4 \times 10^{-3} \mathrm{~s}^{-1}\right)$ was not significantly different from the dissociation rate constant for the DNA containing the phaR promoter region $\left(k_{\text {off }}=0.9 \times 10^{-3} \mathrm{~s}^{-1}\right)$ or that of the control DNA $\left(k_{\text {off }}=0.7 \times 10^{-3} \mathrm{~s}^{-1}\right)$. These parameters indicate that PhaR had higher affinity for the phaP promoter region than for the phaR promoter region. The larger $k_{\text {on }}$ value for the DNA with the phaP promoter region must have been due to the length of the recognition sequence for PhaR in the target DNA region. A 32-bp region TGC-rich sequence is recognized by $\mathrm{PhaR}$ in the 
phaP promoter region, while the phaR promoter region included only an 8-bp recognition sequence (Table 1) (Potter and Steinbuchel 2005). On the basis of the $k_{\text {on }}$ values obtained in this study, the difference in $k_{\text {on }}$ values between the promoter regions of phaP and phaR corresponds to the hypothetical model of PhaR-mediated phaP expression (Maehara et al. 2002; Potter and Steinbuchel 2005; Yamada et al. 2007). In particular, when PHA is not accumulated in the cells, the presence of PhaR is necessary to repress the gene expression of phaP. Since PhaP is a predominantly PHA granule-associated protein, PhaP production is not required for the cells without PHA accumulation (Maehara et al. 2002). Thus, the lower $k_{\text {on }}$ value for DNA with the phaR promoter region indicates weak repression of phaR expression in cells.

In the measurement of PhaR-am-P(3HB) binding, we did not obtain $k_{\text {off }}$ and $K_{\mathrm{d}}$ values of the binding of PhaR to am- $\mathrm{P}(3 \mathrm{HB})$, because the $k_{\text {off }}$ was negative. This result indicates that the binding of $\mathrm{PhaR}$ to am- $\mathrm{P}(3 \mathrm{HB})$ is an irreversible interaction (Table 1 ). There was no significant difference between the $k_{\text {on }}$ value for am- $\mathrm{P}(3 \mathrm{HB})$ $\left(k_{\text {on }}=7.0 \pm 3.8 \times 10^{4} \mathrm{M}^{-1} \mathrm{~s}^{-1}\right)$ and that for the DNA containing the phaP promoter region $\left(k_{\text {on }}=6.0 \pm 0.4 \times 10^{4} \mathrm{M}^{-1} \mathrm{~s}^{-1}\right)$, which implied that the derepression of phaP expression was prompted by an increase in the concentration of am- $\mathrm{P}(3 \mathrm{HB})$ in the cells. In other words, the concentrationdependent effect was one of the main factors initiating the expression of phaP at the onset of the dissociation of PhaR from the phaP promoter region in cells.

In conclusion, we observed initial binding behaviors between PhaR and target molecules such as target DNAs and am- $\mathrm{P}(3 \mathrm{HB})$, using $\mathrm{QCM}$ techniques. Based on the QCM data, kinetic parameters $\left(k_{\text {on }}, k_{\text {off }}\right.$, and $\left.K_{\mathrm{d}}\right)$ for the binding of PhaR to target molecules were determined by the kinetic analysis of obtained binding curves. These values provided a novel insight into the binding behavior of PhaR with target molecules. The phaP gene is likely derepressed in harmony with the ratio of the concentration of the target DNA to the concentration of am- $\mathrm{P}(3 \mathrm{HB})$ at the beginning of $\mathrm{P}(3 \mathrm{HB})$ synthesis in microbes. On the basis of the results of a previous paper (Maehara et al. 2002), we assumed that PhaR dissociates from the PhaR/DNA complex when $\mathrm{P}(3 \mathrm{HB})$ is accumulated under intracellular conditions. This finding indicates that the effector molecules of PhaR are $\mathrm{P}(3 \mathrm{HB})$ molecules. Also, one of the factors responsible for the dissociation of PhaR from DNA is the high affinity of $\mathrm{PhaR}$ to $\mathrm{P}(3 \mathrm{HB})$. The binding of PhaR to DNA and to am- $\mathrm{P}(3 \mathrm{HB})$ showed similar $k_{\text {on }}$ values, suggesting that a concentration-dependent effect caused the expression of phaP with dissociation of PhaR from the phaP promoter region. The insights of the regulation mechanism concerning PhaR in PHA synthesis have the potential to improve the applications of PHA in white and red biotechnology.

\section{Abbreviations}

(PHA): Polyhydroxyalkanoate; (PhaP): Phasin; [P(3HB)]: Poly(3-hydroxybutyrate); [Cr-P(3HB)]: Poly[(R)-3-hydroxybutyrate]; (QCM): Quartz crystal microbalance; $\left(k_{\text {on }}\right)$ : Binding rate constant; $\left(k_{\text {off }}\right)$ : Dissociation rate constant; $\left(K_{d}\right)$ : Dissociation constant; [am-P(3HB)]: Amorphous poly(3-hydroxybutyrate); (SDS): Sodium dodecyl sulfate; (PAGE): Polyacrylamide gel electrophoresis.

\section{Competing interests}

The authors declare that they have no competing interests.

\section{Acknowledgements}

The authors declare no competing financial interest. Supported by RIKEN Biomass Engineering Program.

\section{Author details}

Enzyme Research Team, RIKEN Biomass Engineering Program, RIKEN, 2-1, Hirosawa, Wako-shi, Saitama 351-0198, Japan. ²Department of Biomolecular Engineering, Tokyo Institute of Technology, 4259 Nagatsuta, Midori-ku, Yokohama 226-8501, Japan. ${ }^{3}$ Research Cluster for Innovation, RIKEN, 2-1, Hirosawa, Wako-shi, Saitama 351-0198, Japan. ${ }^{4}$ Present address: Department of Biological Chemistry and Food Science, Faculty of Agriculture, Iwate University, 3-18-8 Ueda, Morioka 020-8550, Japan. ${ }^{5}$ Present address: Frontier Institute for Biomolecular Engineering Research (FIBER), Konan University, 7-1-20 Minatojima-minamimachi, Chuo-ku, Kobe 650-0047, Japan.

Received: 25 December 2012 Accepted: 22 January 2013

Published: 27 January 2013

\section{References}

Backstrom BT, Brockelbank JA, Rehm BH (2007) Recombinant Escherichia coli produces tailor-made biopolyester granules for applications in fluorescence activated cell sorting: functional display of the mouse interleukin-2 and myelin oligodendrocyte glycoprotein. BMC Biotechnol 7:3. doi:10.1186/1472-6750-7-3

Banki MR, Gerngross TU, Wood DW (2005) Novel and economical purification of recombinant proteins: intein-mediated protein purification using in vivo polyhydroxybutyrate (PHB) matrix association. Prot sci publ Prot Soc 14(6):1387-1395. doi:10.1110/ps.041296305

Doi Y, Kitamura S, Abe H (1995) Microbial synthesis and characterization of poly (3-hydroxybutyrate-co-3-hydroxyhexanoate). Macromolecules 28(14):4822-4828

Eugenio LI, Galan B, Escapa IF, Maestro B, Sanz JM, Garcia JL, Prieto MA (2010) The PhaD regulator controls the simultaneous expression of the pha genes involved in polyhydroxyalkanoate metabolism and turnover in Pseudomonas putida KT2442. Environ Microbiol 12(6):1591-1603. doi:10.1111/j.1462-2920.2010.02199.x

Kojima T, Yamane T, Nakano H (2006) In vitro selection of DNA binding sites for transcription factor, PhaR, from Paracoccus denitrificans using genetic library on microbeads and flow cytometry. J Biosci Bioeng 101(5):440-444. doi:10.1263/Jbb.101.440

Maehara A, Taguchi S, Nishiyama T, Yamane T, Doi Y (2002) A repressor protein, PhaR, regulates polyhydroxyalkanoate (PHA) synthesis via its direct tnteraction with PHA. J Bacteriol 184(14):3992-4002. doi:10.1128/Jb.184.14.3992-4002.2002

Matsuno H, Niikura K, Okahata Y (2001) Design and characterization of asparagine- and lysine-containing alanine-based helical peptides that bind selectively to A center dot $\mathrm{T}$ base pairs of oligonucleotides immobilized on a $27 \mathrm{MHz}$ quartz crystal microbalance. Biochemistry-Us 40(12):3615-3622

Okahata Y, Niikura K, Sugiura Y, Sawada M, Morii T (1998) Kinetic studies of sequence-specific binding of GCN4-bZIP peptides to DNA strands immobilized on a 27-MHz quartz-crystal microbalance. Biochemistry-Us 37(16):5666-5672

Potter M, Madkour MH, Mayer F, Steinbuchel A (2002) Regulation of phasin expression and polyhydroxyalkanoate (PHA) granule formation in Ralstonia eutropha H16. Microbiology 148:2413-2426

Potter M, Steinbuchel A (2005) Poly(3-hydroxybutyrate) granule-associated proteins: Impacts on poly(3-hydroxybutyrate) synthesis and degradation. Biomacromolecules 6(2):552-560. doi:10.1021/Bm049401n

Steinbuchel A, Fuchtenbusch B (1998) Bacterial and other biological systems for polyester production. Trend Biotechnol 16(10):419-427 
Sudesh K, Abe H, Doi Y (2000) Synthesis, structure and properties of polyhydroxyalkanoates: biological polyesters. Prog Polym Sci 25(10):1503-1555

Takahashi S, Matsuno H, Furusawa H, Okahata Y (2007) Kinetic analyses of divalent cation-dependent EcoRV digestions on a DNA-immobilized quartz crystal microbalance. Anal Biochem 361(2):210-217. doi:1016/j.ab.2006.11.030

Takahashi S, Matsuno H, Furusawa H, Okahata Y (2008) Direct monitoring of allosteric recognition of type IIE restriction endonuclease EcoRll. J Biol Chem 283(22):15023-15030. doi:1074/jbc.M800334200

Wang Z, Wu H, Chen J, Zhang J, Yao Y, Chen GQ (2008) A novel self-cleaving phasin tag for purification of recombinant proteins based on hydrophobic polyhydroxyalkanoate nanoparticles. Lab on a chip 8(11):1957-1962. doi:10.1039/b807762b

Wang ZH, Ma P, Chen J, Zhang J, Chen CB, Chen GQ (2011) A transferable heterogeneous two-hybrid system in Escherichia coli based on polyhydroxyalkanoates synthesis regulatory protein PhaR. Microbial cell factories 10:21. doi:10.1186/1475-2859-10-21

Yamada M, Yamashita K, Wakuda A, Ichimura K, Maehara A, Maeda M, Taguchi S (2007) Autoregulator protein PhaR for biosynthesis of polyhydroxybutyrate [P (3HB)] possibly has two separate domains that bind to the target DNA and P (3HB): Functional mapping of amino acid residues responsible for DNA binding. J Bacteriol 189(3):1118-1127. doi:10.1128/Jb.01550-06

Yamashita K, Yamada M, Numata K, Taguchi S (2006) Nonspecific hydrophobic interactions of a repressor protein, PhaR, with poly[(R)-3-hydroxybutyrate] film studied with a quartz crystal microbalance. Biomacromolecules 7(8):2449-2454. doi:10.1021/Bm0604420

doi:10.1186/2191-0855-3-6

Cite this article as: Yamada et al:: Monitoring and kinetic analysis of the molecular interactions by which a repressor protein, PhaR, binds to target DNAs and poly[(R)-3-hydroxybutyrate]. AMB Express 2013 3:6.

\section{Submit your manuscript to a SpringerOpen ${ }^{\circ}$ journal and benefit from:}

- Convenient online submission

- Rigorous peer review

- Immediate publication on acceptance

- Open access: articles freely available online

- High visibility within the field

- Retaining the copyright to your article

Submit your next manuscript at $\gg$ springeropen.com 